\title{
Quantitative Imaging of Young's Modulus of Soft Tissues from Ultrasound Water Jet Indentation: A Finite Element Study
}

\author{
Min-Hua Lu, ${ }^{1,2,3}$ Rui Mao, ${ }^{4}$ Yin Lu, ${ }^{3}$ Zheng Liu, ${ }^{3}$ Tian-Fu Wang, ${ }^{1,2,3}$ and Si-Ping Chen ${ }^{1,2,3}$ \\ ${ }^{1}$ National-Regional Engineering Laboratory for Key Technology of Medical Ultrasound, Shenzhen University, \\ Shenzhen 518060, China \\ ${ }^{2}$ Guangdong Key Laboratory of Biomedical Information Detection and Ultrasound Imaging, Shenzhen University, \\ Shenzhen 518060, China \\ ${ }^{3}$ Department of Biomedical Engineering, School of Medicine, Shenzhen University, Shenzhen 518060, China \\ ${ }^{4}$ Shenzhen Key Labratory of Service Computing and Applications, College of Computer Science and Software Engineering, \\ Shenzhen University, Shenzhen 518060, China \\ Correspondence should be addressed to Min-Hua Lu, minhua_lu@hotmail.com
}

Received 2 June 2012; Accepted 8 July 2012

Academic Editor: Huafeng Liu

Copyright () 2012 Min-Hua Lu et al. This is an open access article distributed under the Creative Commons Attribution License, which permits unrestricted use, distribution, and reproduction in any medium, provided the original work is properly cited.

Indentation testing is a widely used approach to evaluate mechanical characteristics of soft tissues quantitatively. Young's modulus of soft tissue can be calculated from the force-deformation data with known tissue thickness and Poisson's ratio using Hayes' equation. Our group previously developed a noncontact indentation system using a water jet as a soft indenter as well as the coupling medium for the propagation of high-frequency ultrasound. The novel system has shown its ability to detect the early degeneration of articular cartilage. However, there is still lack of a quantitative method to extract the intrinsic mechanical properties of soft tissue from water jet indentation. The purpose of this study is to investigate the relationship between the loading-unloading curves and the mechanical properties of soft tissues to provide an imaging technique of tissue mechanical properties. A 3D finite element model of water jet indentation was developed with consideration of finite deformation effect. An improved Hayes' equation has been derived by introducing a new scaling factor which is dependent on Poisson's ratios $v$, aspect ratio $a / h$ (the radius of the indenter/the thickness of the test tissue), and deformation ratio $d / h$. With this model, the Young's modulus of soft tissue can be quantitatively evaluated and imaged with the error no more than $2 \%$.

\section{Introduction}

Physiologic processes may change tissue properties significantly. Tissue elasticity is one of the typical mechanical properties which generally correlate with pathological changes [1], such as cancer [2] and osteoarthritis [3]. During the past a few decades, there have been many efforts to develop various techniques to measure or image the elasticity of soft tissue, such as elastography [4-6], indentation [7-9], and atomic force elasticity microscopy [10-12].

Indentation is one of the most commonly used method to measure mechanical properties of soft tissues in situ or in vivo, because it does not require special preparation of regular shaped tissues and can be employed to perform tests on small specimens [13]. A typical application of indentation is to assess the degeneration of articular cartilage (AC). AC is often characterized as a single phase, isotropic, homogeneous linear elastic model when no interstitial fluid flows during instantaneous, and equilibrium responses [7, 8]. Rigid cylindrical flat-ended or spherical indenters have been employed in early models of indentation, and the Young's modulus of soft tissues [14-16] can be calculated using the following equation given by Hayes et al. [7]:

$$
E=\frac{\left(1-v^{2}\right)}{2 a k(v, a / h)} \cdot \frac{F}{d}
$$

where $F$ is the indentation force, $v$ is the Poisson's ratio of soft tissues, $a$ is the radius of indenter, $h$ is the tissue thickness, $d$ is the indentation depth, and $k$ is a scaling factor, which depends on aspect ratio $a / h$ and Poisson's ratio $v$. It is emphasized that the deformation was assumed to be small, 
which is difficult to be controlled when indentation test is performed manually [9]. Zhang et al. developed a finite element model using (1) by including the effects of large deformation up to $15 \%$ strain, and a new set of $k$ values were calculated [14].

Young's modulus can be calculated from (1) by using experimentally obtained data of $F$ and $d$. The indentation force $F$ is normally recorded by a force sensor. The deformation $d$ can be measured by optical $[17,18]$, needle probe [19-21] or ultrasound $[9,22-25]$ methods. Poisson's ratio $v$ is conventionally assumed to be an assigned value $[7,15]$ or separately measured using other methods $[13,16,26]$. Among them, ultrasound measurement provides a noninvasive and accurate tool for obtaining both tissue thickness and deformation simultaneously. Nevertheless, traditional ultrasound indentation typically operates at the frequency range between 2 and $10 \mathrm{MHz}$ and is normally used to measure the mechanical properties of entire tissue layers. Its resolution is not sufficient to map the mechanical properties of soft tissues with fine structures. Moreover, most of current indentation instruments use a contact way, so that tissue damage caused by the measurement instrumentation cannot be avoided. High frequency ultrasound can improve the resolution to a microscopic level. However, for some technical reason, high frequency ultrasound transducers are not suitable for traditional contact indentation [27]. Considering that ultrasound can propagate through water with very small attenuation, $\mathrm{Lu}$ et al. [28] developed a water jet system to achieve noncontact high frequency $(20-50 \mathrm{MHz})$ ultrasound indentation. Water jet not only serves as a soft indenter but also as the coupling medium for high-frequency ultrasound.

The ultrasound water jet indentation system has been employed to obtain modulus image of soft tissues [27], to assess articular cartilage degeneration [29] and to evaluate the bone-tendon junction healing progress [28], which has shown great potential to image the modulus distribution of soft tissues for clinical assessment and diagnosis, and/or to perform indentation tests on small specimens at microscopic levels for biological tissues and other materials. However, all the studies mentioned above measured the stiffness ratio of soft tissue as an indicator of tissue pathological state, which is not the intrinsic property of soft tissue. There's still large discrepancy between the values of stiffness ratio and Young's modulus.

In this study, we simulated the water jet indentation using finite element (FE) analysis to investigate the interaction between fluid (water jet) and solid (soft tissue). With this FE model, the Young's modulus of soft tissue can be calculated using an improved indentation solution based on Hayes' equation by introducing the geometry-, material- and deformation-dependent factor $k$. A new set of scaling factor $k$ is presented by considering the finite deformation effect of indentation.

\section{Methods}

The water jet indentation system consists of a 3D translating device (Arthroscopic supporting arm, Medtronic Inc., MN,

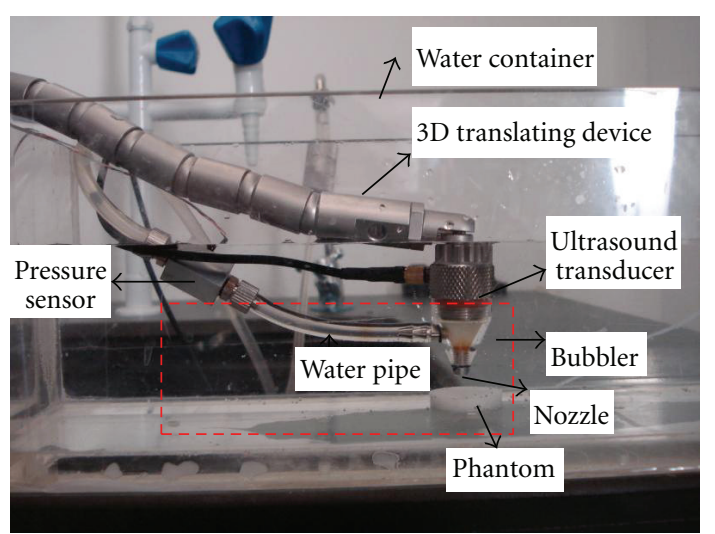

FIGURE 1: Diagram of the noncontact ultrasound indentation system. The 3D translating device facilitated the system to move easily and monitor the deformation of the phantom. Water flowed from the water pipe and water jet was used as an indenter. Focused highfrequency ultrasound was transmitted through water. The central square region, including a long water pipe, a bubbler, a nozzle, and the soft phantom, was modeled in ANSYS WORKBENCH (see Figure 2). Pressure sensor was located $60 \mathrm{~mm}$ from the middle of the bubbler. The dimensions of the important components are: nozzle diameter $1.7 \mathrm{~mm}$, water supply pipe diameter $2 \mathrm{~mm}$, the height of nozzle is $8.5 \mathrm{~mm}$ and the distance from the nozzle to tissue approximately $0.95 \mathrm{~mm}$.

USA), a water container, a pressure sensor (EPB-C12, Entran Devices, Inc., Fairfield, NJ, USA), a water pipe, an ultrasound transducer (SEUT-506, Acoustic Sensor Co., Ltd., Taiwan), a bubbler, and a nozzle (Figure 1). The 3D translating device facilitates the system to move easily to adjust the distance from the transducer to the tissue sample, and to apply C-scan to obtain modulus image of the region of interest. Focused high-frequency ultrasound is transmitted through the bubbler when it is filled up with water. The central frequency of the ultrasound transducer is $50 \mathrm{MHz}$, with focal length at $12 \mathrm{~mm}$, and aperture size at $6 \mathrm{~mm}$. The dimensions of the important components are nozzle diameter $1.7 \mathrm{~mm}$, water supply pipe diameter $2 \mathrm{~mm}$, the height of nozzle is $8.5 \mathrm{~mm}$, and the distance from the nozzle to tissue approximately $0.95 \mathrm{~mm}$ which is determined by adjusting the ultrasound beam focused at tissue surface. Pressure sensor was located $60 \mathrm{~mm}$ from the middle of the bubbler.

A three-dimensional finite element (FE) model whose geometry was as same as the experimental system was established using ANSYS (version 11.0, Canonsburg, PA, USA) to simulate indentation (Figure 2). The interaction between the water jet and soft tissue involves fluid and structural solid coupling, therefore, the simulation was performed by computational fluid dynamics (CFD) analysis that was performed in ANSYS CFX 11 and ANSYS 11 structural codes, coupled through the ANSYS MFX solver. One-way fluidstructure interaction (FSI) theory was applied in this problem.

2.1. Model Geometries. The fluid domain model is shown as Figure 2. The dimensions of the important components are 


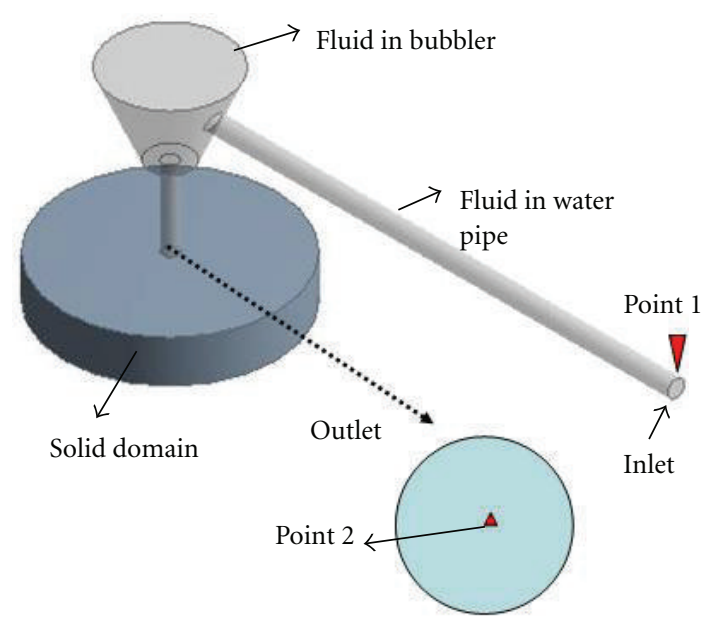

FIgUre 2: Model of the water jet indentation in ANSYS. The upper part represents fluid domain, which included a long water pipe with $60 \mathrm{~mm}$ in length, a bubbler, and a nozzle. To make the outlet clearer, an enlarged part was displayed at the right bottom. Radius of inlet was $1 \mathrm{~mm}$ and outlet $0.85 \mathrm{~mm}$. Point 1 , the upper point of inlet, and Point 2, the central point of outlet, were set as two monitoring points. The lower part represents solid domain. Diameters of the tissue phantom was $25 \mathrm{~mm}$ and its thickness was $5 \mathrm{~mm}$.

totally same as the experimental system described above. The CFX-Mesh method was applied to mesh the fluid domain. With consideration of velocity gradients in near-wall regions, inflation theory was used. In our study, when the flow rate at the inlet was increased from $1 \mathrm{~m} / \mathrm{s}$ to $10 \mathrm{~m} / \mathrm{s}$, different meshes influenced the results significantly. After a proper grid sensitivity analysis, the number of inflated layers was set as 11 and the maximum thickness of inflated boundary was set as $0.1 \mathrm{~mm}$. Triangle elements were generated outside of the boundary layer regions. Refinement of the mesh is implemented at the boundaries. Totally a mesh of 665242 nodes and 2877024 elements were employed for all simulations.

The model of solid part is built up as a cylinder soft tissue with its thickness at $5 \mathrm{~mm}$ and diameter at $25 \mathrm{~mm}$. The patch conforming mesher under tetrahedrons is used. Regular meshes consisting of about 101911 nodes and 65034 elements were adopted, after a proper grid sensitivity analysis, for all the models developed.

2.2. Boundary Conditions. The simulated indentation test considers a specimen supported by a rigid impermeable plate and indented by water jet from the nozzle. One-way FSI was adopted in our study, therefore, the fluid part and solid part were modeled separately. After fluid models were solved, pressure calculated from fluid outlet was mapped to the contact region of soft tissue.

The following boundary conditions were imposed on all the fluid models. (1) Inlet boundary was adopted at the beginning of the water pipe, with speed varied from $1 \mathrm{~m} / \mathrm{s}$ to $10 \mathrm{~m} / \mathrm{s}$ and intensity of $5 \%$ of turbulence model was used. (2) Outlet boundary was defined at the interface of fluid and relative pressure was $0 \mathrm{~Pa}$. (3) Wall influence on flow is defined as no slip and wall roughness as smooth wall. As to the solid model, the nodes were constrained in the vertical direction at the bottom of the specimen and pressure was mapped from the fluid outlet to specimen surface.

2.3. Material Properties. Water at $22^{\circ} \mathrm{C}$ was used for the fluid models. Soft tissue was assumed to be a linear-elastic, homogeneous, and isotropic thin layer adhere to a rigid foundation $[15,16]$. The mechanical properties were described by Young's modulus $E$ and Poisson's ratio $v$. Different values of Young's modulus obtained from literature review and our previous studies, $10 \mathrm{kPa}, 52 \mathrm{kPa}, 146 \mathrm{kPa}, 270 \mathrm{kPa}, 740 \mathrm{kPa}$, and $1000 \mathrm{kPa}$ were assigned to the tissue model in FE analysis to mimic human normal liver, human diseased liver, breast benign lesion, breast malignant lesion, cancerous skin, and articular cartilage, respectively, [30-32]. Density of the soft tissue was $1060 \mathrm{~kg} / \mathrm{m}^{3}$.

2.4. Extract of Young's Modulus of Soft Tissue. Different from the traditional indentation, our water-jet indenter can be regarded as a "soft indenter", therefore, Hayes' equation cannot be used to derive Young's modulus from the forcedisplacement curve obtained with our experimental system anymore. An improved indentation solution was proposed by taking into account the finite deformation effect as

$$
E=\frac{\left(1-v^{2}\right)}{2 a k(v, a / h, d / h)} \cdot \frac{F}{d},
$$

therefore,

$$
k\left(v, \frac{a}{h}, \frac{d}{h}\right)=\frac{\left(1-v^{2}\right)}{2 a E} \cdot \frac{F}{d},
$$

where $E$ is Young's modulus, $F$ is the indentation force which was calculated by the FE simulation, $v$ is the Poisson's ratio of soft tissues which was generally assumed as the values reported by literature review, $a$ is the radius of indenter and $h$ is the tissue thickness which can be obtained in advance before an indentation test, $d$ is the indentation depth which was assigned to the nodes on the upper surface of the indenter during the simulation of indentation test, and $k$ is a scaling factor, which depends on aspect ratio $a / h$, deformation ratio $d / h$, and Poisson's ratio $v$.

The simulated force-deformation data were used to calculate the Young's modulus and then derive the $k$ value. These new $k$ values were calculated using (3). Then the Young's modulus of the soft tissues under water jet indentation can be calculated by substituting these new $k$-values to (2). Different fixed Poisson's ratio $(v=0.1-0.5)$, indentation depth $(0.1 \%-10 \%)$, and aspect ratio $a / h(0.17,0.4,0.6,0.8$, and 1) were also assigned to the tissue model to investigate the effects of these factors on the estimation of Young's modulus. Therefore, we have a total of 1650 simulation processes in this study.

\section{Results}

First, the relationship between the pressure (or flow rate) measured at the inlet and the total force applied to the soft 


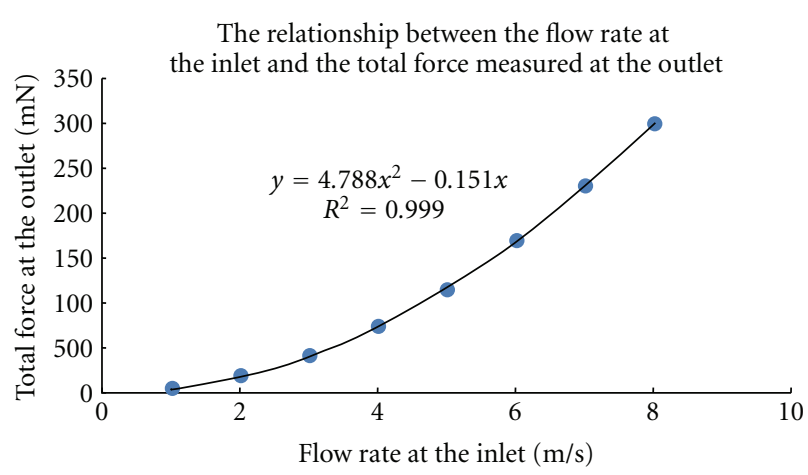

Figure 3: The relationship between the flow rate measured from Point 1 at inlet and the force calculated from Point 2 at outlet.

tissue was analyzed. This relationship is crucial because it is difficult for us to directly measure the force applied to the soft tissue by water jet during experiment. Two measurement points were set at the inlet and outlet (Points 1 and 2 as indicated in Figure 2), respectively. Figure 3 shows a quadratic function that fit the flow rate measured from Point 1 at inlet and the force calculated from Point 2 at outlet. Figure 4 shows the relationship between the flow rate and the pressure measured both at Point 1 at inlet. The nonlinear but monotonic relationship indicates that we may measure only pressure or flow rate at the inlet to calculate the force applied to the soft tissue. It will highly facilitate the water jet indentation when it is used in clinical applications.

Table 1 shows the $k$ values with different aspect ratios (0.17-1.0), Poisson's ratios (0.1-0.5), and deformation ratios (0.01-0.1). The $k$ values increased with the increase of aspect ratios and Poisson's ratios. However, the nonlinear and nonmonotonic relationships between the $k$ values and deformation ratio were found.

In comparison with the ground truth, the percentage errors of the calculated Young's moduli are between $-0.07 \%$ and $-1.47 \%$ when the aspect ratio varied from 0.17 and 1 , which suggested a quite good agreement between the actual and calculated values of Young's modulus.

\section{Discussion}

In this study, a 3D FE model was constructed to simulate the water jet indentation on soft tissues. One-way fluid-solid coupling analysis was conducted to find the relationship among the parameters of the indentation force, tissue deformation, tissue Young's modulus and Poisson's ratio and the aspect parameters, including the indenter size and tissue sample size. An improved Hayes' equation was developed to calculate Young's modulus of soft tissue from the forcedeformation curve by introducing a new scaling factor $k$. A new set of $k$ values for different Poisson's ratio $v$, aspect ratio $a / h$, and strain level $d / h$ were calculated. We also investigated the relationship of the water parameters, such as pressure and flow rate, in the water jet indentation system and the influence of these parameters on the indentation force. The percentage errors of the estimated Young's modulus ranged

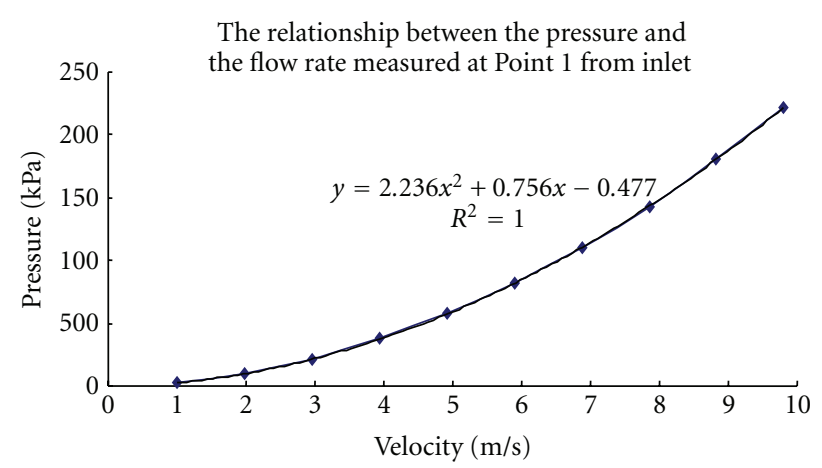

FIGURE 4: The correlation between the pressure and the flow rate measured both at Point 1 from inlet.

from $-0.07 \%$ to $-1.47 \%$ in comparison with the assigned values in FE simulation when the aspect ratio $a / h$ ranged from 0.17 to 1 . This robustness of the estimation could be further improved by averaging the parameters calculated using different deformation levels.

It has been demonstrated that our system can measure the Young's modulus of the soft tissue under water jet indentation at one single site. As shown in Figure 1, a flexible arm is used as the supporting arm to control the water jet indenter in this system. This arm, actually utilized the system to conduct C-scan over the tissue sample easily. Cscan imaging provides a useful view of an object, showing a plane perpendicular to the ultrasound beam. It has been widely used in the aerospace industry to detect the surface corrosion, delaminations, voids, cracks and other faults in aging aircraft $[33,34]$. In our study, it's easy to apply C-scan with different water pressures for C-scan sequences. After analyzing both the ultrasound signal and flow rate collected from different C-scans, the modulus image could be obtained.

The water jet ultrasound indentation system has been proven that it is useful for the assessment of tissue pathology. Tissue elasticity is one important parameter which generally correlates with tissue pathological changes. This study, for the first time, extracts Young's modulus of soft tissue from water jet indentation using FE analysis. In our FE model, soft tissue is assumed as a linear elastic, homogeneous and isotropic material. However, biphasic theory suggests that most tissues are composed of solid and fluid materials, and they possess very complicated structure-function behaviors and exhibit time-dependent behavior, that is, nonlinear or visco-elastic, heterogeneous and anisotropic behavior. Normally, solid matrix represents the elastic properties while fluid materials represent the viscous properties. In order to interpret these complicated behaviors of soft tissues, the acquired force-deformation data should be interpreted carefully by taking the biphasic theory of soft tissue into accounts.

This study only focused on the nonlinear effect caused by the finite deformation of indentation. The nonlinear and visco-elastic properties of soft tissues have not been addressed yet. Studies on nonlinear tissues' models [35] and indentation of anisotropic biomaterials [36] have been reported. In the future study, the effects of nonlinear 
TABLE 1: The scaling factor $(k)$ used in this study for different aspect ratios $(a / h)$, Poisson's ratios $(v)$, and deformation ratios $(d / h)$.

\begin{tabular}{|c|c|c|c|c|c|c|}
\hline \multirow[b]{2}{*}{$d / h$} & \multicolumn{6}{|c|}{ Poisson's ratio } \\
\hline & 0.10 & 0.20 & 0.30 & 0.40 & 0.45 & 0.50 \\
\hline \multicolumn{7}{|c|}{$a / h=0.17$} \\
\hline 0.001 & 0.8009 & 0.8050 & 0.8112 & 0.8215 & 0.8306 & 0.8379 \\
\hline 0.01 & 0.7924 & 0.7967 & 0.8043 & 0.8171 & 0.8277 & 0.8385 \\
\hline 0.05 & 0.7532 & 0.7565 & 0.7662 & 0.7858 & 0.8015 & 0.8248 \\
\hline 0.07 & 0.7343 & 0.7354 & 0.7471 & 0.766 & 0.7825 & 0.8102 \\
\hline \multicolumn{7}{|c|}{$a / h=0.4$} \\
\hline 0.001 & 0.9307 & 0.9422 & 0.9617 & 0.9963 & 1.0254 & 1.0909 \\
\hline 0.01 & 0.9266 & 0.9384 & 0.9589 & 0.9957 & 1.0261 & 1.0961 \\
\hline 0.05 & 0.9074 & 0.92 & 0.9437 & 0.9886 & 1.0261 & 1.1129 \\
\hline 0.1 & 0.8827 & 0.8945 & 0.9199 & 0.9712 & 1.0149 & 1.1186 \\
\hline \multicolumn{7}{|c|}{$a / h=0.6$} \\
\hline 0.001 & 1.0721 & 1.0918 & 1.1278 & 1.1948 & 1.2526 & 1.3683 \\
\hline 0.01 & 1.0695 & 1.0896 & 1.1267 & 1.1965 & 1.2564 & 1.3782 \\
\hline 0.05 & 1.0572 & 1.079 & 1.1204 & 1.2011 & 1.2715 & 1.4181 \\
\hline 0.1 & 1.0407 & 1.0632 & 1.1087 & 1.2002 & 1.2822 & 1.4643 \\
\hline \multicolumn{7}{|c|}{$a / h=0.8$} \\
\hline 0.001 & 1.2303 & 1.2628 & 1.3208 & 1.4338 & 1.5346 & 1.7026 \\
\hline 0.01 & 1.2289 & 1.2621 & 1.3217 & 1.4368 & 1.542 & 1.7191 \\
\hline 0.05 & 1.2225 & 1.2581 & 1.3240 & 1.4566 & 1.5771 & 1.7923 \\
\hline 0.1 & 1.2135 & 1.2513 & 1.3237 & 1.4744 & 1.6152 & 1.8761 \\
\hline \multicolumn{7}{|c|}{$a / h=1.0$} \\
\hline 0.001 & 1.4239 & 1.4715 & 1.5601 & 1.7385 & 1.9 & 2.197 \\
\hline 0.01 & 1.4238 & 1.4722 & 1.5628 & 1.7465 & 1.9128 & 2.2257 \\
\hline 0.05 & 1.4227 & 1.4746 & 1.5738 & 1.7803 & 1.973 & 2.3573 \\
\hline 0.1 & 1.4204 & 1.4759 & 1.5847 & 1.8364 & - & - \\
\hline
\end{tabular}

visco-elaticity, inhomogeneity and anisotropy should be considered. Another issue is about the structure of the tissue model. In this study, tissue model with a single layer was developed. However, in most cases, soft tissues are multilayers and behave complex. Our high frequency ultrasound can differentiate tissue layers with high resolution. Hence, for a further study, soft tissues with multi-layers should be considered in the model, so that, both the depth-dependent and site-dependent Young's modulus distribution can be imaged with our system. What's more, experiments about indentation with the water jet indentation system will be conducted, and results will be compared with those obtained from this FE study.

\section{Acknowledgments}

This work acknowledges the support of the National Natural Science Foundation of China (nos. 60901015, 61031003, 61170076) and the Basic Science Research Fund of Shenzhen (nos. JC200903120032A, JC201006020025A, JC201005280408 A). We also would like to deliver our appreciation to Mr. Ruichao Sun for his contribution in the construction of the FE model and all the academic discussions.

\section{References}

[1] Y. C. Fung, Biomechanics: Mechanical Properties of Living Tissues, Spring, 1993.

[2] T. R. Tilleman, M. M. Tilleman, and M. H. A. Neumann, "The elastic properties of cancerous skin: Poisson's ratio and Young's modulus," Israel Medical Association Journal, vol. 6, no. 12, pp. 753-755, 2004.

[3] M. Stolz, R. Gottardi, R. Raiteri et al., "Early detection of aging cartilage and osteoarthritis in mice and patient samples using atomic force microscopy," Nature Nanotechnology, vol. 4, no. 3, pp. 186-192, 2009.

[4] O. Rouvière, M. Yin, M. A. Dresner et al., "MR elastography of the liver: preliminary results," Radiology, vol. 240, no. 2, pp. 440-448, 2006.

[5] A. S. Khalil, R. C. Chan, A. H. Chau, B. E. Bouma, and M. R. K. Mofrad, "Tissue elasticity estimation with optical coherence elastography: toward mechanical characterization of in vivo soft tissue," Annals of Biomedical Engineering, vol. 33, no. 11, pp. 1631-1639, 2005.

[6] J. F. Greenleaf, M. Fatemi, and M. Insana, "Selected methods for imaging elastic properties of biological tissues," Annual Review of Biomedical Engineering, vol. 5, pp. 57-78, 2003.

[7] W. C. Hayes, G. Herrmann, L. F. Mockros, and L. M. Keer, "A mathematical analysis for indentation tests of articular cartilage," Journal of Biomechanics, vol. 5, no. 5, pp. 541-551, 1972. 
[8] A. F. Mak, W. M. Lai, and V. C. Mow, "Biphasic indentation of articular cartilage-I. Theoretical analysis," Journal of Biomechanics, vol. 20, no. 7, pp. 703-714, 1987.

[9] Y. P. Zheng and A. F. T. Mak, "An ultrasound indentation system for biomechanical properties assessment of soft tissues in-vivo," IEEE Transactions on Biomedical Engineering, vol. 43, no. 9, pp. 912-918, 1996.

[10] A. Ebert, B. R. Tittmann, J. Du, and W. Scheuchenzuber, "Technique for rapid in vitro single-cell elastography," Ultrasound in Medicine and Biology, vol. 32, no. 11, pp. 1687-1702, 2006.

[11] N. Gavara and R. S. Chadwick, "Noncontact microrheology at acoustic frequencies using frequency-modulated atomic force microscopy," Nature Methods, vol. 7, no. 8, pp. 650-654, 2010.

[12] D. C. Hurley, M. Kopycinska-Müller, A. B. Kos, and R. H. Geiss, "Nanoscale elastic-property measurements and mapping using atomic force acoustic microscopy methods," Measurement Science and Technology, vol. 16, no. 11, pp. 21672172, 2005.

[13] H. Jin and J. L. Lewis, "Determination of Poison's ratio of articular cartilage by indentation using different-sized indenters," Journal of Biomechanical Engineering, vol. 22, no. 7, pp. 843-848, 2004.

[14] M. Zhang, Y. P. Zheng, and A. F. T. Mak, "Estimating the effective Young's modulus of soft tissues from indentation testsnonlinear finite element analysis of effects of friction and large deformation," Medical Engineering and Physics, vol. 19, no. 6, pp. 512-517, 1997.

[15] M. H. Lu and Y. P. Zheng, "Indentation test of soft tissues with curved substrates: a finite element study," Medical and Biological Engineering and Computing, vol. 42, no. 4, pp. 535-540, 2004.

[16] A. P. C. Choi and Y. P. Zheng, "Estimation of Young's modulus and Poisson's ratio of soft tissue from indentation using two different-sized indentors: finite element analysis of the finite deformation effect," Medical and Biological Engineering and Computing, vol. 43, no. 2, pp. 258-264, 2005.

[17] A. S. Khalil, R. C. Chan, A. H. Chau, B. E. Bouma, and M. R. K. Mofrad, "Tissue elasticity estimation with optical coherence elastography: toward mechanical characterization of in vivo soft tissue," Annals of Biomedical Engineering, vol. 33, no. 11, pp. 1631-1639, 2005.

[18] Y. P. Huang, Y. P. Zheng, S. Z. Wang, Z. P. Chen, Q. H. Huang, and Y. H. He, "An optical coherence tomography (OCT)-based air jet indentation system for measuring the mechanical properties of soft tissues," Measurement Science and Technology, vol. 20, no. 1, Article ID 015805, 11 pages, 2009.

[19] D. M. Ebenstein and L. A. Pruitt, "Nanoindentation of biological materials," Nano Today, vol. 1, no. 3, pp. 26-33, 2006.

[20] C. Li, L. A. Pruitt, and K. B. King, "Nanoindentation differentiates tissue-scale functional properties of native articular cartilage," Journal of Biomedical Materials Research A, vol. 78, no. 4, pp. 729-738, 2006.

[21] L. Ng, H. H. Hung, A. Sprunt, S. Chubinskaya, C. Ortiz, and A. Grodzinsky, "Nanomechanical properties of individual chondrocytes and their developing growth factor-stimulated pericellular matrix," Journal of Biomechanics, vol. 40, no. 5, pp. 1011-1023, 2007.

[22] L. P. Han, J. A. Noble, and M. Burcher, "A novel ultrasound indentation system for measuring biomechanical properties of in vivo soft tissue," Ultrasound in Medicine and Biology, vol. 29, no. 6, pp. 813-823, 2003.
[23] K. Mori, Y. Nakagawa, H. Kuroki et al., "Non-contact evaluation for articular cartilage using ultrasound," JSME International Journal A, vol. 49, no. 2, pp. 242-249, 2006.

[24] P. Kiviranta, E. Lammentausta, J. Töyräs, I. Kiviranta, and J. S. Jurvelin, "Indentation diagnostics of cartilage degeneration," Osteoarthritis and Cartilage, vol. 16, no. 7, pp. 796-804, 2008.

[25] K. Hattori, K. Ikeuchi, Y. Morita, and Y. Takakura, "Quantitative ultrasonic assessment for detecting microscopic cartilage damage in osteoarthritis," Arthritis Research \& Therapy, vol. 7, no. 1, pp. 38-46, 2005.

[26] Y. P. Zheng, A. P. C. Choi, H. Y. Ling, and Y. P. Huang, "Simultaneous estimation of Poisson's ratio and Young's modulus using a single indentation: a finite element study," Measurement Science and Technology, vol. 20, no. 4, Article ID 045706, 9 pages, 2009.

[27] M. H. Lu and Y. P. Zheng, "A novel method to obtain modulus image of soft tissues using ultrasound water jet indentation: a phantom study," IEEE Transactions on Biomedical Engineering, vol. 54, no. 1, pp. 114-121, 2007.

[28] M. H. Lu, Y. P. Zheng, Q. H. Huang et al., "Noncontact evaluation of articular cartilage degeneration using a novel ultrasound water jet indentation system," Annals of Biomedical Engineering, vol. 37, no. 1, pp. 164-175, 2009.

[29] M. H. Lu, Y. P. Zheng, H. B. Lu, Q. H. Huang, and L. Qin, "Evaluation of bone-tendon junction healing using water jet ultrasound indentation method," Ultrasound in Medicine and Biology, vol. 35, no. 11, pp. 1783-1793, 2009.

[30] F. J. Carter, T. G. Frank, P. J. Davies, D. McLean, and A. Cuschieri, "Measurements and modelling of the compliance of human and porcine organs," Medical Image Analysis, vol. 5, no. 4, pp. 231-236, 2001.

[31] A. Athanasiou, A. Tardivon, M. Tanter et al., "Breast lesions: quantitative elastography with supersonic shear imagingpreliminary results," Radiology, vol. 256, no. 1, pp. 297-303, 2010.

[32] H. Abe, K. Hayashi, and M. Sato, Data Book on Mechanical Properties of Living Cells, Tissue and Organs, Spring, Tokyo, Japan, 1996.

[33] S. Birks and R. E. Green, Nondestructive Testing Handbook: Ultrasonic Testing, American Society for Nondestructive Testing, Columbus, Ohio, USA, 1991.

[34] M. Lasser, B. Lasser, J. Kula, and G. Rohrer, "On-line, large area ultrasonic imaging for composite manufacturing," in Proceedings of the The American Society for Nondestructive Testing, Phoenix, Arizona, October 1999.

[35] Y. Liu, A. E. Kerdok, and R. D. Howe, "A nonlinear finite element model of soft tissue indentation," Lecture Notes in Computer Science, vol. 3078, pp. 67-76, 2004.

[36] J. E. Bischoff, "Static indentation of anisotropic biomaterials using axially asymmetric indenters-a computational study," Journal of Biomechanical Engineering, vol. 126, no. 4, pp. 498$505,2004$. 


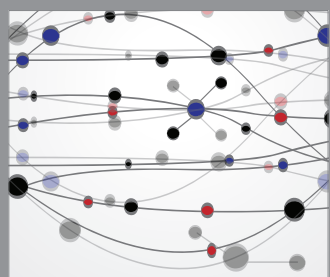

The Scientific World Journal
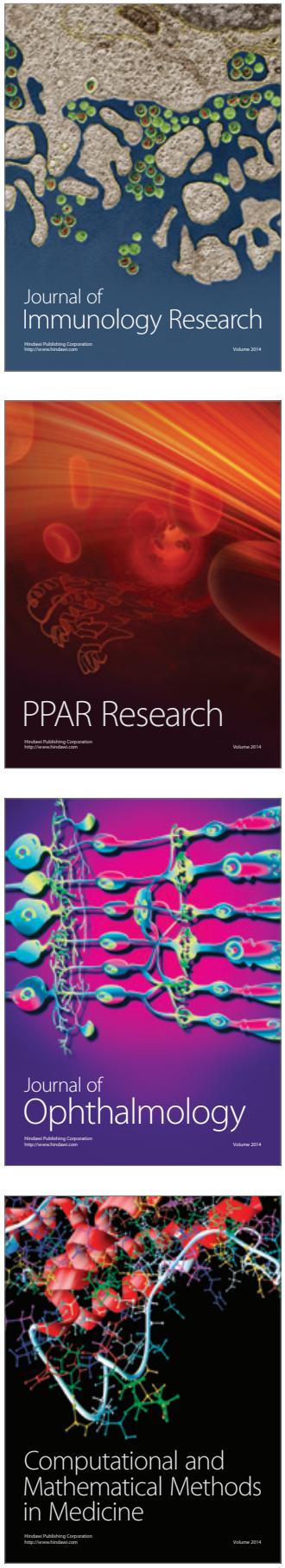

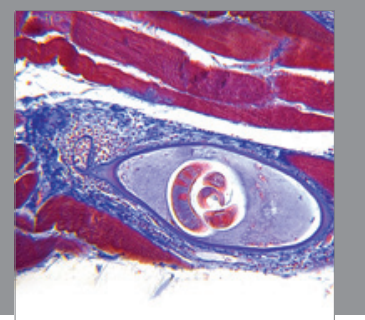

Gastroenterology

Research and Practice
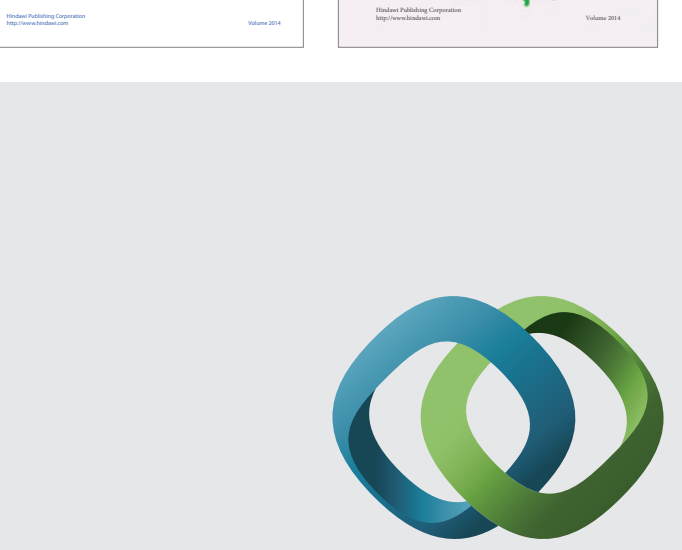

\section{Hindawi}

Submit your manuscripts at

http://www.hindawi.com
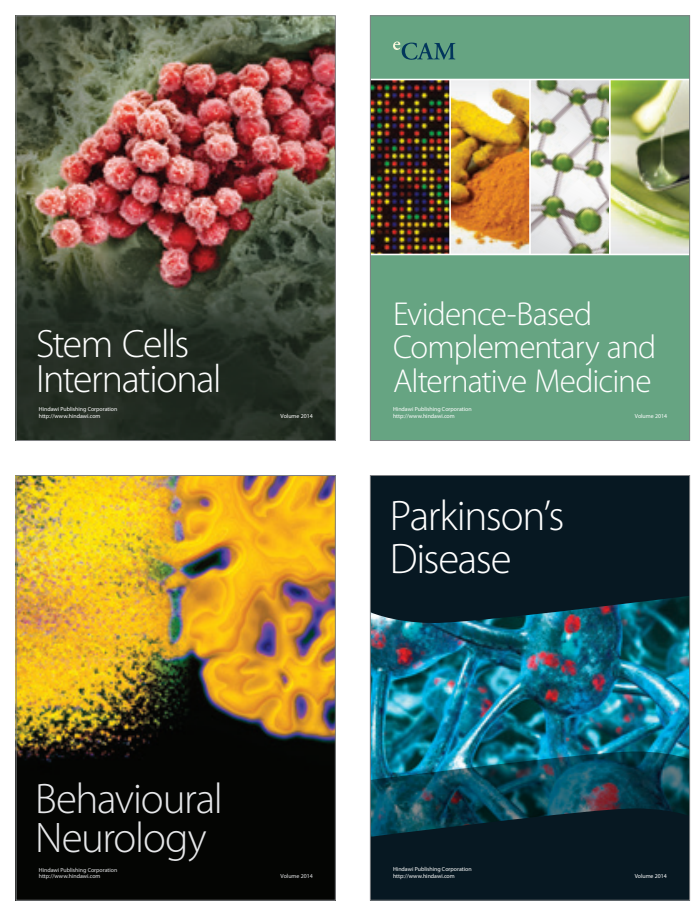

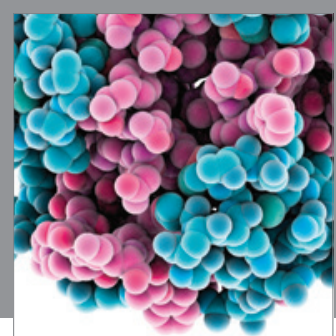

Journal of
Diabetes Research

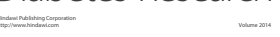

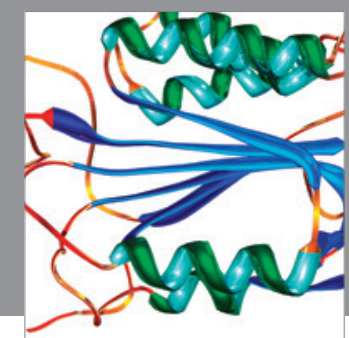

Disease Markers
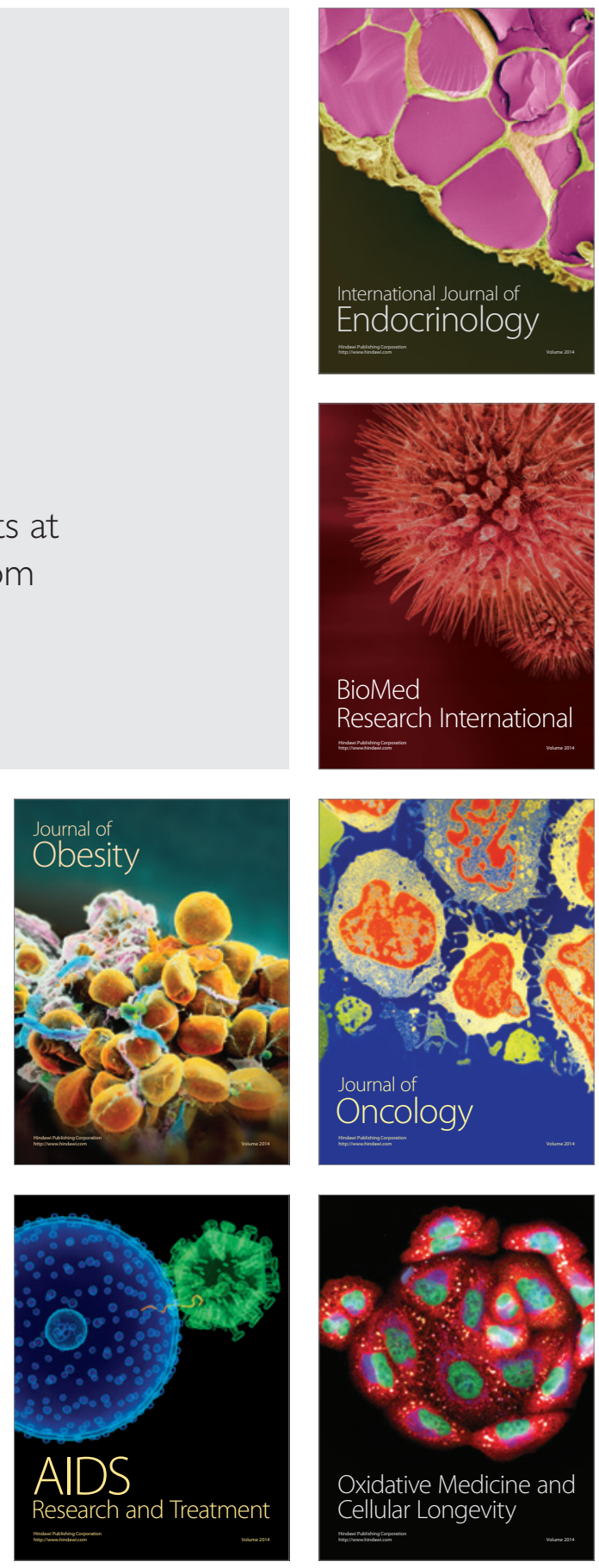